estudos RBEP

\title{
Diálogos entre ciência e religião: a temática sob a ótica de futuros professores*
}

\author{
Bernardo Valentim Riceto ${ }^{\mathrm{I}, \text { II }}$ \\ Pedro Donizete Colombo Junior ${ }^{\text {III, IV }}$
}

http://dx.doi.org/10.24109/2176-6681.rbep.100i254.3797

\footnotetext{
* Agradecemos aos licenciandos dos oito cursos de licenciatura da UFTM e seus respectivos coordenadores pela disponibilidade e aceitação em participar da presente pesquisa. Destaca-se, por fim, que esta pesquisa foi submetida ao e aprovada pelo Comitê de Ética da UFTM, CAAE 51407315.6.0000.5154, $\mathrm{n}^{\circ}$ parecer: 1.439 .558$.

I Universidade Federal do Triângulo Mineiro (UFTM). Uberaba, Minas Gerais, Brasil. E-mail: < bernardo_riceto@ hotmail.com $>$; < http://orcid. org/0000-0001-5821-6400>.

II Licenciado em nível de graduação em Física pela Universidade Federal do Triângulo Mineiro (UFTM). Uberaba, Minas Gerais, Brasil.

III Universidade Federal do Triângulo Mineiro (UFTM). Uberaba, Minas Gerais, Brasil. E-mail: < pedro.colombo@ uftm.edu.br $>$; < http://orcid. org/0000-0003-3324-5859>.

IV Doutor em Ensino de Física pela Universidade de São Paulo (USP). São Paulo, São Paulo, Brasil.
}

\section{Resumo}

Ciência e religião adquiriram, ao longo dos séculos, vieses que se cruzam e se afastam em caminhos tortuosos, segundo concepções de natureza filosófica, contextos políticos, sociais e influências econômicas. Esta pesquisa buscou investigar que visão graduandos de diferentes cursos de licenciatura fazem da relação entre ciência e religião e como interpretam essa relação em um contexto de sala de aula. Objetivou-se identificar e analisar visões de alunos, ingressantes e concluintes, de todos os cursos de licenciatura da Universidade Federal do Triângulo Mineiro (UFTM), campus Uberaba, Minas Gerais, Brasil. Também fez parte desta pesquisa o diálogo com os coordenadores de cada curso participante, com o intuito de apresentar os dados analisados e ter um feedback deste trabalho. Foi adotada metodologia de pesquisa qualitativa e quantitativa com aplicação de questionários aos licenciandos e de entrevistas semiestruturadas aos coordenadores. Entre os resultados, destacou-se o de que, em alguns cursos (e áreas), há uma significativa variação na visão dos licenciandos sobre como trabalhar a temática ciência e religião em sala de aula. Ficou evidente também que entre os concluintes há uma maior tendência de diálogo sobre a relação ciência e religião.

Palavras-chave: ciência e religião; formação de professores; concepções de licenciandos. 


\section{Abstract \\ Dialogues between science and religion: the theme through the perspective of teachers in training}

Over the centuries, science and religion have taken facets that cross and pull away in tortous paths, according to philosophical conceptions, economic influences, as well as political and social contexts. This research investigates the notions harbored by undergraduates of different teachertraining courses on the relation between science and religion and what they make of it in a classroom context. The aim is to identify and analyze the views of new-entrant and exiting students enrolled in all of the teachertraining courses in the Uberaba's campus of the Federal University of Triângulo Mineiro (UFTM), Minas Gerais, Brazil. Also figuring in the research is the dialogue with the coordinators of each of the implicated courses, which aims to present the data analyzed and to get a feedback from it.

The chosen research methodology was the qualitative and quantitative; it was also applied questionnaires to students and semi-structured interviews to course coordinators. Among the results, it stands out that, in some courses (and areas), there is a significant variation in the students' conceptions on how science and religion should be approached in the classroom. Thus, it is also evident that among exiting students there is a higher tendency for a dialogue between science and religion.

Keywords: science and religion; teacher training; students' conceptions.

\section{Resumen \\ Diálogos entre ciencia y religión: la temática bajo la óptica de futuros profesores}

La ciencia y la religión han adquirido, a lo largo de los siglos, sesgos que se cruzan y se alejan en caminos tortuosos, según concepciones de naturaleza filosófica, contextos políticos, sociales e influencias económicas. Este estudio buscó investigar qué visión graduandos de diferentes cursos de formación de profesores tienen de la relación entre ciencia y religión y cómo la interpretan en un contexto de aula. Se objetivó identificar y analizar visiones de alumnos, ingresantes y concluyentes de todos los cursos de formación de profesores de la Universidad Federal del Triángulo Mineiro (UFTM), campus Uberaba, Minas Gerais, Brasil. También hizo parte de esta investigación el diálogo con los coordinadores de cada carrera participante, con el fin de presentar los datos analizados y tener un feedback de este trabajo. Se adoptó metodología de investigación cualitativa y cuantitativa con aplicación de cuestionarios a los graduandos y de entrevistas semiestructuradas a los coordinadores. Entre los resultados, se destacó que, en algunos cursos (y áreas), hay una 
significativa variación en la visión de los graduandos sobre cómo trabajar la temática ciencia y religión en el aula. Es evidente también que entre los concluyentes hay una mayor tendencia de diálogo sobre la relación ciencia y religión.

Palabras clave: ciencia y religión; formación de profesores; concepciones de graduandos.

\section{Comentários iniciais}

A procura por respostas é algo que sempre instigou e motivou a humanidade. A medida que o conhecimento vai sendo construído, algumas perguntas encontram respostas, enquanto outras surgem em um movimento que informa e (de)forma a construção de conhecimentos, sejam eles científicos ou teológicos. O conhecimento científico, por ter um caráter de logicidade, busca explicar uma grande variedade de fenômenos que ocorrem ao nosso redor, estando em constante modificação. Já o teológico, muitas vezes revestido de revelações divinas, busca na crença e na fé suas bases de sustentação.

Assim, enquanto o conhecimento teológico tende a explicar assuntos que envolvam, por exemplo, a finalidade do homem na Terra, a existência, a eternidade e a relação do homem com Deus, o conhecimento científico busca explicar a natureza, suas causas e fenômenos mais imediatos. Entretanto, em relação a muitas temáticas, essas duas vertentes não seguiram caminhos isolados, pelo contrário, têm se cruzado ao longo dos séculos. Nesses cruzamentos, se por um lado ocorrem diálogos e consensos, por outro, surgem inflamadas discussões diante de pontos de vista divergentes e ideias conflitantes sobre os assuntos em voga.

Quando se atenta à educação básica, não é incomum que os encontros e desencontros entre ciência e religião acarretem inúmeras dúvidas e conflitos, seja pelo conteúdo ministrado, postura e crença do aluno, seja pelo posicionamento do professor. Sobre este último aspecto, some-se o pseudopreparo dos professores em trabalhar essa temática de forma neutra e reflexiva com os alunos. Tal fato se agrava no momento em que os alunos ficam imersos em uma atmosfera de opiniões divergentes, as quais confundem e dificultam o discernimento do que é estudado, por exemplo, em temas controversos. Um cenário que inquieta e nos leva a pensar como a dicotomia ciência-religião - e a nuvem de temas que a circundam - é interpretada por licenciandos, futuros professores, mediadores em sala de aula.

Nesse contexto, esta pesquisa teve como objetivo investigar aspectos da relação entre ciência e religião em âmbito acadêmico, em particular a partir da visão de licenciandos dos oito cursos de formação de professores da Universidade Federal do Triângulo Mineiro (UFTM), campus Uberaba, Minas Gerais. Optamos por fazer uma análise envolvendo diferentes áreas do conhecimento - humanas, exatas e biológicas - a fim de verificar em quais pontos, sobre a temática em questão, as concepções dos licenciandos se afastam e em quais pontos convergem. Buscamos instigar os participantes a revelarem seu próprio saber em forma de afirmações, 
contradições e rupturas de convicções. Além disso, buscamos também levar ao conhecimento dos coordenadores de curso os resultados encontrados, discutindo, entre outros aspectos, possíveis momentos em que a relação ciência-religião poderia surgir dentro das matrizes curriculares dos cursos e, posteriormente, em sala de aula da educação básica.

Em seu aspecto metodológico, a pesquisa contou com a elaboração e aplicação de questionários para alunos do primeiro período (ingressantes) e do oitavo período (concluintes) de cada curso de licenciatura da UFTM. Ademais, o estudo foi estendido para os coordenadores dos cursos mediante entrevistas semiestruturadas, sendo o tratamento dos dados realizado por meio de compilação, cruzamento de informações, análises e inferências.

Ressaltamos que, neste artigo, não dispomos de espaço suficiente para discutir todas as relações existentes entre ciência e religião, seja em aspectos da história humana ou de frentes religiosas. Também é oportuno destacar que não temos como propósito discutir verdades e/ou mentiras em âmbito das religiões, tampouco da ciência. Dessa forma, recortes se fizeram necessários, com predominância de um viés cristão, em particular das religiões derivadas dessa vertente. Isso se deve ao fato de estas terem material mais abundante à nossa disposição, não cabendo, no entanto, à pesquisa empregar juízo de valor quanto a outras vertentes religiosas e suas percepções de mundo. Esperamos apresentar e discutir a visão de licenciandos que possam colaborar para o (re)pensar da temática em salas de aula da educação básica, quiçá nos cursos de formação inicial de professores.

\section{A interface ciência e religião}

De fato, desde os primórdios da humanidade, ciência e religião se relacionam. Por vezes, as crenças religiosas influenciaram o conhecimento científico e, ao mesmo tempo, este provocou mudanças, por vezes profundas, em doutrinas religiosas. A ideia de uma divindade sempre esteve presente para a espécie humana e, de certa forma, ditou a conduta do ser humano sobre diversos aspectos da vida, principalmente em relação à sua visão sobre os fenômenos da natureza. Tanto a ciência quanto a religião podem ser entendidas como criações humanas, portanto, sujeitas a modificações e adaptações ao longo do tempo.

Em determinados momentos da antiguidade, os corpos celestes foram identificados pelo homem como as principais divindades. Ciência e religião se entrelaçavam na busca de um melhor entendimento dos fenômenos naturais, ou seja, a aproximação entre os dois campos de conhecimento era maior que o afastamento em suas interpretações.

Falar a respeito das interações entre dois corpos de conhecimento já supõe a sua distinção. Tal suposição teria parecido algo sem sentido para os eruditos medievais, para os quais teologia e filosofia natural existiam fundidas em um corpo abrangente de conhecimento. (Alexander, 2007, p. 1, tradução nossa).

É interessante pensar que, na antiguidade, muitas concepções que buscavam elucidar o universo traziam consigo erros que a ciência não conseguia esclarecer e recaíam, assim, em explicações que constituíam quase um ato de fé, por exemplo, a da ideia de heliocentrismo. No entanto, 
à medida que foi se construindo a história por meio de relatos, contos e experiências vividas, a religião começou a sofrer mais influência das escrituras do que a ciência, trilhando assim seu caminho (resistente à mudança e quebra de paradigma) até os dias atuais. Por outro lado, a ciência, de épocas em épocas, depara-se com novas descobertas, as quais colocam à prova conceitos e leis e fazem repensar as visões de mundo, em um movimento de interpretações efêmeras, nunca possuidora de verdades absolutas.

Ocorre que, no âmbito da educação e dos processos de ensino e aprendizagem, o encontro dessas duas vertentes de conhecimentos foge à tranquilidade desejada. A divulgação do conhecimento científico trabalhado nas escolas tem sido frequentemente confrontada por ideias religiosas, o que não constitui novidade, em face do desenvolvimento científico construído ao longo dos séculos. Tais discussões ocorrem também em âmbito acadêmico e de formação de professores, como observado em diversas pesquisas científicas.

Em "Comparando os objetivos e métodos da ciência e religião na formação de professores", Henrique e Silva (2011) analisam os resultados de uma atividade desenvolvida, na Universidade de São Paulo (USP), durante curso de História da Cosmologia, em que foram discutidas diferentes teorias sobre a origem do universo. O objetivo dos autores foi o de investigar as concepções sobre a natureza da ciência, particularmente sobre as relações entre ciência e religião, estabelecidas pelos licenciandos. $\mathrm{O}$ artigo relata que tanto visões que se aproximavam da ciência quanto as de cunho religioso foram explicitadas pelos alunos durante a atividade. Quando indagados sobre que postura o professor de ciências deveria adotar em sala de aula - por exemplo, sobre o tema criacionismo x evolucionismo -, $25 \%$ dos alunos opinaram que não se deveria falar sobre religião, $25 \%$ defenderam que se deveria falar, mas a partir da perspectiva evolucionista, e 50\% argumentaram sobre a importância da discussão ser realizada de forma neutra.

Em "História da ciência e religião: uma proposta para discutir a Natureza da Ciência", Forato, Pietrocola e Martins (2007) têm como foco principal mostrar que a ciência não é somente oriunda do pensamento racional desenvolvido pelo positivismo. O episódio abordado pelos autores é o da elaboração e do desenvolvimento das ideias de atração e repulsão desenvolvidas por Isaac Newton (1643-1727). Os autores buscam evidenciar a importância de utilizar não apenas métodos científicos na construção do conhecimento, mas também processos baseados em ideias metafísicas.

Trazer a influência de fatores normalmente considerados como não científicos em trabalhos admitidos como científicos permite apresentar aspectos dos complexos processos envolvidos no fazer científico. (Forato; Pietrocola; Martins, 2007, p. 7).

Alexander (2007) compara quatro modelos que discutem a relação entre ciência e religião, analisando vantagens e desvantagens de cada modelo. São eles: (i) Modelo do Conflito, em que a ciência e a religião são irreconciliáveis; (ii) Magistérios Não Interferentes (MNI), em que ambos, religião e ciência, operam em áreas separadas, bastante distintas entre si, o que leva a concluir que não pode haver conflitos entre essas duas 
vertentes; (iii) Modelos de Fusão, em que se tem a busca por explicar a religião com a ciência e vice-versa; e (iv) Modelo da Complementaridade - o mais apropriado na visão do autor, traz uma abordagem baseada nas ideias desenvolvidas por Niels Bohr para explicar o comportamento ondulatório e corpuscular da matéria. Nas palavras do autor, ignorar um nível em favor do outro empobrece a compreensão da personalidade humana. Para Alexander (2007), não existe um modelo único que resolva todos os problemas e discussões, mas o da complementaridade é apontado como um caminho para a temática da relação entre ciência e religião.

Já Lima e Menin (2006) apresentam a realidade enfrentada por professores em sala de aula. Foram observadas dez escolas públicas, sendo que quatro (com maiores incidências religiosas) foram escolhidas para a análise, com especial atenção para aulas nas disciplinas de português, matemática e ciências. As autoras destacam que, por vezes, as escolas têm trazido valores religiosos como prontos e acabados, nos moldes de transmissão, não deixando espaço para o processo de descoberta por parte do aluno, aproximando-se de um caráter doutrinário.

Inúmeras outras pesquisas sobre a temática ciência e religião têm sido desenvolvidas tanto em cenário nacional quanto internacional. Dorvillé (2010) analisa os conflitos enfrentados pelos licenciandos evangélicos do curso de Ciências Biológicas da Universidade do Estado do Rio de Janeiro (UERJ), buscando identificar as suas visões de mundo e as formas como eles encaram os conteúdos acadêmicos - em especial, temas relacionados à evolução biológica. El-Hani e Sepúlveda (2004) analisam como os alunos protestantes do curso de licenciatura em Ciências Biológicas da Universidade Estadual de Feira de Santana (UEFS) e seus professores encaram a relação ciência e religião; analisam também quais as estratégias utilizadas para conviverem em um ambiente onde suas visões de mundo eventualmente se chocam. Woolnough (1996), em pesquisa realizada no Reino Unido, critica a abordagem positivista lógica na qual se produz uma visão de mundo limitada, eliminando muito da experiência humana; defendem a consciência de diferentes tipos de conhecimento, com diferentes critérios de verdade. Loving e Foster (2000) investigam qual a posição de pós-graduandos norteamericanos sobre a compatibilidade entre ciência e religião; buscam, assim, identificar o quanto os pós-graduandos estão preparados para conduzir discussões sobre ciência e religião nas aulas de ciências.

Essa breve retomada do estado da arte evidencia a importância da temática ciência e religião e como essa relação tem sido alvo de muitas discussões no âmbito das pesquisas acadêmicas. Fato que justifica e autoriza a presente pesquisa na formação inicial de professores.

\section{Delineando o aporte teórico-metodológico da pesquisa}

Ante os objetivos delineados, buscamos analisar as visões de licenciandos sobre a temática ciência e religião. Os participantes são alunos (ingressantes e concluintes) dos oito cursos de licenciatura da Universidade Federal do Triângulo Mineiro (UFTM), campus Uberaba/ MG: Ciências Biológicas, Física, Química, Matemática, Letras, Geografia, História e Educação do Campo. 
Escala com as opções "discordo totalmente", "discordo parcialmente", "indiferente", "concordo parcialmente", "concordo totalmente".

2 No momento da realização da pesquisa, o curso de Educação do Campo, por ser recente na UFTM, não possuía turmas no oitavo período (concluintes); participaram da pesquisa alunos do primeiro e do quarto períodos do curso.
O curso de Letras iniciou as atividades na UFTM no segundo semestre de 2006, sendo o primeiro curso de licenciatura da instituição. Já os cursos de licenciatura em Ciências Biológicas, Física, Química, Matemática, Geografia e História iniciaram suas atividades em 2009, sendo viabilizados pelas ações do plano de Reestruturação e Expansão das Universidades Federais (Reuni). Por último, voltado prioritariamente para as populações do campo, o curso de licenciatura em Educação do Campo iniciou suas atividades no final do ano de 2014, com duas áreas de habilitação - Ciências da Natureza ou Matemática.

Para o desenvolvimento da pesquisa, foram adotadas abordagens qualitativa e quantitativa (Lüdke; André, 1986; Bogdan; Biklen, 1994; Gil, 2008), com aplicação de questionários aos licenciandos e entrevistas semiestruturadas aos coordenadores de todos os cursos. Destaca-se que a construção de algumas questões do questionário aplicado aos licenciandos foi adaptada de outras investigações (Souza et al., 2009; Dorvillé, 2010; Henrique; Silva, 2011).

De modo a balizar nossas ações de pesquisa, buscamos refletir sobre possíveis relações existentes entre as diferentes áreas do conhecimento quanto à temática ciência e religião, bem como sobre a existência (ou não) de diferenças e similaridades de posicionamento entre ingressantes e formandos quando se trata da relação entre as temáticas. Nesse contexto, surgiram diversas questões para investigação, por exemplo: Que leitura os futuros professores fazem de temas polêmicos, como big bang, evolução darwinista, clonagem, células-tronco embrionárias, alimentos transgênicos, entre outros?

Buscando responder às questões que surgiram no decorrer da pesquisa, a aplicação de questionários (com questões abertas, de múltipla escolha e com escala Likert $^{1}$ ) ocorreu em dois momentos distintos da formação docente: com alunos ingressantes de primeiro período e com alunos concluintes de oitavo ${ }^{2}$. A escolha de aplicar questionários foi motivada pelo grande número de participantes na pesquisa. Compartilhamos das ideias de Gil (2008), para quem a opção pelo questionário não expõe os pesquisados à influência de opiniões e de seu aspecto pessoal. A participação dos alunos foi voluntária, tendo adesão de 99\% dos licenciandos, totalizando 263 alunos (divididos nas 16 turmas, com $70 \%$ de alunos ingressantes e $30 \%$ de concluintes).

Para a coleta de dados com os coordenadores dos cursos, optamos por utilizar uma entrevista semiestruturada, o que, segundo Lüdke e André (1986, p. 34), "pode permitir o aprofundamento de pontos levantados por outras técnicas de coleta de alcance mais superficial". O número de coordenadores, por ser reduzido, permitiu esse tipo de aprofundamento, o que nos forneceu valiosas informações. Optamos por gravar as entrevistas para garantir que todas as informações apresentadas pelos coordenadores pudessem ser registradas e facilitassem as análises. Como forma de examinar os dados, debruçamonos sobre a exploração dos materiais escritos e gravados coletados no decorrer da pesquisa, visando à tabulação de respostas, ao cruzamento de informações e à busca por inferências e descrições que sustentassem conclusões para a investigação. 


\section{Resultados e discussões}

Devido à grande quantidade de dados apurados, realizamos recortes para a construção deste artigo, mantendo, contudo, a essência dos resultados encontrados. Inicialmente, de modo a caracterizar os participantes da pesquisa, explicitamos alguns dados de cunho socioeconômico.

De acordo com o aspecto socioeconômico, a maioria dos licenciandos, em torno de $70 \%$, estudaram todas as etapas de educação básica em escola pública, $27 \%$ em escola particular e somente $3 \%$ em ambos os tipos - resultado característico das licenciaturas, que destoa de cursos tradicionais da UFTM, como Medicina.

O curso de Ciências Biológicas foi o que apresentou a maior parcela de alunos provenientes de escolas particulares (41\%). Questionado sobre esse dado, o coordenador informou que a maioria dos alunos que opta por Ciências Biológicas o faz por aptidão, escolha ou afinidade com a área, o que resulta também em uma menor taxa de evasão na universidade. Por outro lado, o curso de licenciatura em Educação do Campo foi o que apresentou menor número de alunos provenientes da rede privada de ensino, o que segundo a coordenação se deve às especificidades do curso.

Quanto à idade dos participantes, quase metade dos licenciandos ingressantes se enquadram na faixa etária entre 17 e 20 anos, já os concluintes, entre 21 e 24 anos (Gráfico 1). Destaca-se que cerca de $20 \%$ dos alunos ingressantes tinham idade acima de 28 anos e estavam buscando uma segunda graduação.

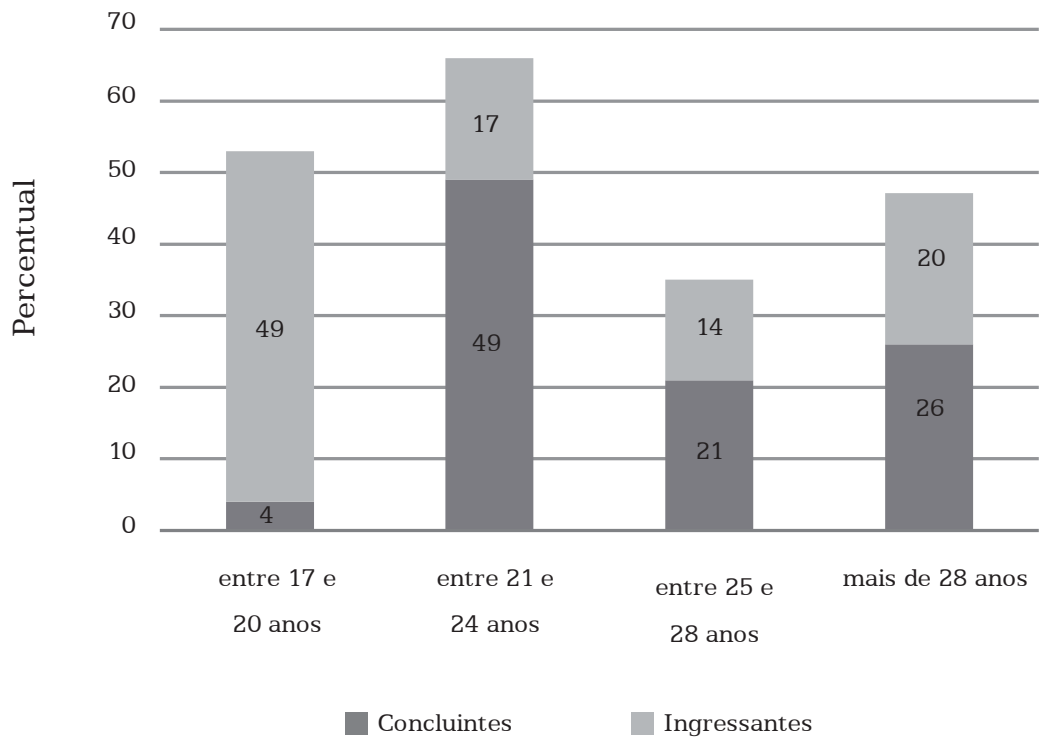

\section{Gráfico 1 - Faixa etária de ingressantes e concluintes participantes da pesquisa}

Fonte: Elaboração própria. 
O curso de Letras foi o que teve alunos com a faixa etária mais alta. Na turma do primeiro período, 39\% dos alunos tinham mais de 28 anos. A coordenadora explicou que o curso de Letras recebe muitos alunos já graduados, frequentemente oriundos de cursos como Direito e Pedagogia. De acordo com a coordenadora, são alunos que buscam mais qualificação para o mercado de trabalho, aperfeiçoamento da língua portuguesa e de línguas estrangeiras, como o espanhol e/ou inglês.

Já o curso que teve a faixa etária mais baixa foi o de Ciências Biológicas. Diante desse dado, o coordenador reforçou o argumento de que grande parte dos alunos são provenientes de escolas particulares, escolhem esse curso na infância ou adolescência e, ao concluírem a educação básica, já ingressam na universidade.

Sobre a religião praticada pelos licenciandos, 57,9\% responderam enquadrar-se em duas categorias: católica e espiritualista. A maioria $(34,7 \%)$ informou ser católica (Tabela 1). Dados publicados pelo Instituto Brasileiro de Geografia e Estatística (IBGE), em 2012, mostraram que a porcentagem de católicos no Brasil era de 64,6\%, muito acima do obtido na UFTM. Por outro lado, ainda de acordo com o IBGE, a quantidade de espiritualistas (de religião kardecista, umbanda ou candomblé) era de $2,3 \%$, enquanto na UFTM, de $23,2 \%$. Inferimos que a significativa diferença entre os dados nacionais e os encontrados na pesquisa se deve ao fato de a cidade de Uberaba/MG ter sido o local de trabalho do famoso médium espírita Francisco Cândido Xavier, mais conhecido como Chico Xavier.

Tabela 1 - Percentual de alunos segundo a religião, por curso

\begin{tabular}{|c|c|c|c|c|c|c|c|c|c|}
\hline & 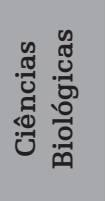 & 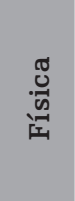 & 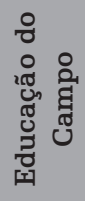 & 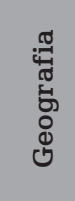 & 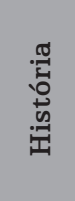 & & 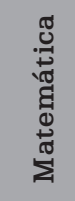 & 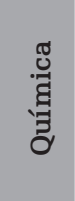 & 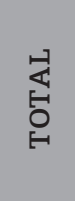 \\
\hline Ateu & 6,4 & 8,3 & 0,0 & 3,3 & 10,6 & 9,8 & 3,1 & 6,3 & 6,6 \\
\hline Agnóstico & 10,6 & 16,7 & 0,0 & 10,0 & 17,0 & 2,0 & 15,6 & 31,3 & 11,4 \\
\hline Católico & 40,4 & 25,0 & 83,3 & 26,7 & 17,0 & 31,4 & 40,6 & 25,0 & 34,7 \\
\hline Evangélico & 8,5 & 25,0 & 8,3 & 13,3 & 14,9 & 13,7 & 6,3 & 18,8 & 12,9 \\
\hline Espiritualista & 27,7 & 12,5 & 0,0 & 36,7 & 27,7 & 27,5 & 25,0 & 6,3 & 23,2 \\
\hline Outra & 4,3 & 8,3 & 8,3 & 10,0 & 12,8 & 11,8 & 9,4 & 12,5 & 9,6 \\
\hline $\begin{array}{l}\text { Não } \\
\text { informou }\end{array}$ & 2,1 & 4,2 & 0,0 & 0,0 & 0,0 & 3,9 & 0,0 & 0,0 & 1,5 \\
\hline
\end{tabular}

Fonte: Elaboração própria. 
Analisando a opção religiosa dos alunos, encontramos algumas características bastante peculiares: o curso de Química foi o que mais apresentou alunos agnósticos (31,3\%); o de História tinha a maior quantidade de ateus $(10,6 \%)$ e a menor quantidade de católicos $(17 \%)$; o de Geografia possuía o maior número de espiritualistas (36,7\%); o de Física apresentou uma parcela considerável de alunos evangélicos (25\%); e o de Educação do Campo possuía a maior parcela de alunos católicos (83,3\%). Esses dados são relevantes para a interpretação e as análises realizadas ante a visão dos alunos sobre a relação entre ciência e religião.

Sobre a participação dos alunos em suas "comunidades" religiosas (escala de "nenhuma" a "muita"), os cursos de Ciências Biológicas e Química foram os que indicaram a menor frequência de participação. No de Química, a opção "nenhuma" foi a mais escolhida pelos licenciandos $(35,7 \%)$, fato que pode estar ligado à constatação de ser esse o curso com a maior quantidade de agnósticos. Já o curso de Educação do Campo foi o que obteve resultado mais alto, uma vez que $74 \%$ dos alunos responderam ter "muita" participação em suas "comunidades" religiosas (Gráfico 2), o que pode estar ligado ao fato de $83,3 \%$ dos alunos assumirem-se como católicos.

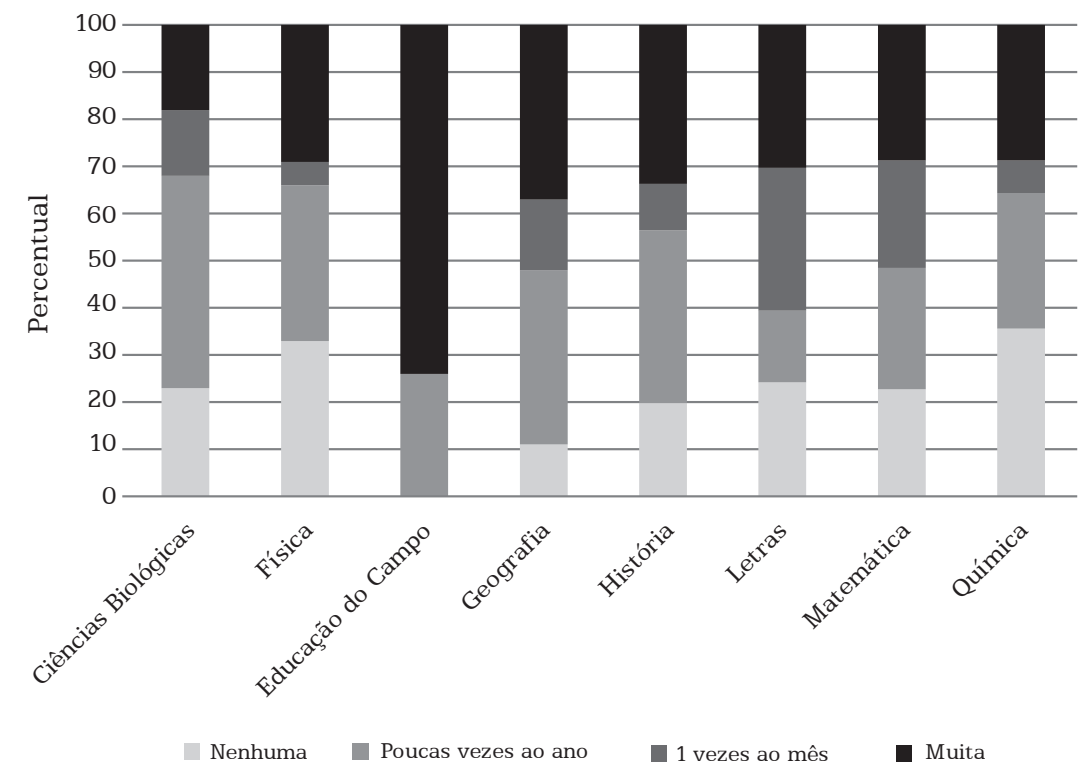

Gráfico 2 - Frequência dos alunos em suas comunidades religiosas,
por curso

Fonte: Elaboração própria.

Em entrevista, a coordenadora de Educação do Campo informou que o perfil dos alunos deste curso é bastante distinto. A religião tem uma importância capital na vida deles e na comunidade em que vivem. $\mathrm{Na}$ percepção da coordenadora, grande parte dos alunos são muito religiosos e "em diversos momentos utilizam do raciocínio religioso para explicar as coisas, para argumentar, e criam uma visão de mundo pautada nisso". 
Segundo ela, esse comportamento dos alunos, em algumas situações, opõe-se à formação científica que os professores propõem em sala de aula, além de influenciar a formação política desses alunos.

Nesta pesquisa, quando indagados se a ciência fornecia respostas plausíveis e confiáveis acerca dos fenômenos naturais (Souza et al., 2009, questão adaptada), os alunos dos cursos de Geografia, História e Química foram os que mais responderam "sim" (Gráfico 3).

Souza et al. (2009), em pesquisa realizada com licenciandos da Universidade Estadual de Londrina (UEL), obtiveram resultados que vão de encontro aos aqui apresentados, apontando uma tendência dos alunos a dar maior credibilidade para a ciência nos cursos de Física, Ciências Biológicas e Química. Os autores constataram que 70,3\% dos alunos do curso de Física, na UEL, responderam "sim" à pergunta de se a ciência oferece respostas plausíveis e confiáveis acerca dos fenômenos naturais; nos cursos de Geografia e História, o percentual de resposta "às vezes" foi mais alto.

Na UFTM, o percentual ficou próximo de 58,3\% para o curso de Física (Gráfico 3). Questionada sobre o dado, a coordenadora afirmou que ele pode estar relacionado à estrutura curricular do curso, ou seja, ao fato de, logo no início da graduação, os licenciandos já entrarem em contato com disciplinas que abordam aspectos da epistemologia e da natureza da ciência.

Outra comparação interessante com os dados encontrados por Souza et al. (2009) é referente aos cursos de Geografia e História, que, como antecipamos, obtiveram o maior número de respostas "às vezes" para o questionamento de se a ciência fornece ou não respostas plausíveis e confiáveis acerca dos fenômenos naturais. Na UFTM, os cursos de Geografia e de História ficaram entre os que obtiveram maior quantidade de resposta "sim". Indagados sobre esse resultado, ambos os coordenadores não fizeram inferências sobre os cursos em particular, apresentando como motivo provável para as respostas o perfil e as escolhas religiosas dos alunos, os quais em sua maioria são espiritualistas (Geografia 36,7\% e História 27,7\%).

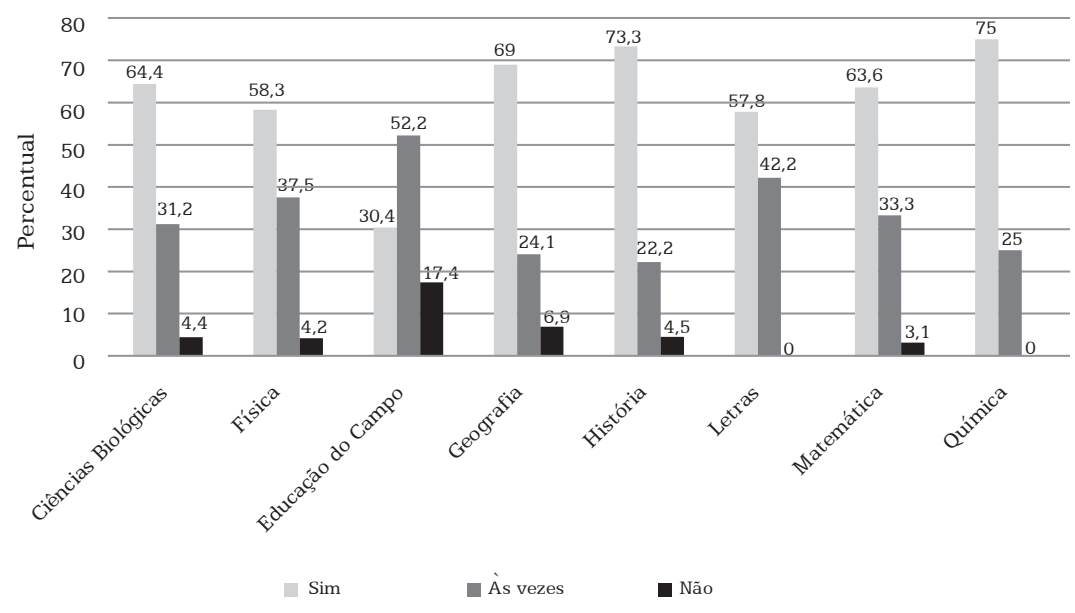

Gráfico 3 - Percepção dos alunos sobre o fato de a ciência fornecer (ou não) respostas plausíveis e confiáveis acerca dos fenômenos naturais, por curso

Fonte: Elaboração própria. 
Buscando investigar qual a aceitação dos licenciandos ante temas polêmicos e/ou controversos da ciência, perguntamos se eles aprovam ou não os trabalhos realizados pela comunidade científica sobre: clonagem de animais, mercado de carbono, clonagem de humanos, experimentação animal, células-tronco embrionárias, entre outros temas (Tabela 2).

Tabela 2 - Percentual de aceitação dos alunos diante de temas polêmicos e/ou controversos da ciência, por curso

\begin{tabular}{|c|c|c|c|c|c|c|c|c|c|}
\hline & 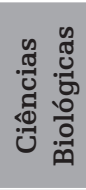 & 苟 & 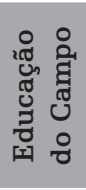 & 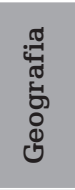 & 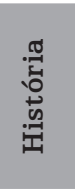 & 总 & 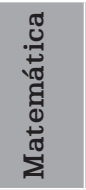 & 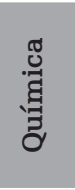 & 䀡 \\
\hline $\begin{array}{l}\text { Clonagem de } \\
\text { animais }\end{array}$ & 42,2 & 70,8 & 27,3 & 44,8 & 57,8 & 46,7 & 54,5 & 50,0 & 49,4 \\
\hline $\begin{array}{l}\text { Mercado de } \\
\text { carbono }\end{array}$ & 43,5 & 90,0 & 25,0 & 56,0 & 50,0 & 55,0 & 45,5 & 50,0 & 50,6 \\
\hline $\begin{array}{l}\text { Clonagem de } \\
\text { humanos }\end{array}$ & 20,0 & 33,3 & 4,5 & 24,1 & 24,4 & 17,8 & 57,6 & 56,3 & 52,9 \\
\hline $\begin{array}{l}\text { Experimentação } \\
\text { animal }\end{array}$ & 43,5 & 68,2 & 52,4 & 31,0 & 20,0 & 37,8 & 42,4 & 43,8 & 47,1 \\
\hline $\begin{array}{l}\text { Células-tronco } \\
\text { embrionárias }\end{array}$ & 97,8 & 95,7 & 57,1 & 86,2 & 95,6 & 95,2 & 27,3 & 6,3 & 20,8 \\
\hline $\begin{array}{l}\text { Origem do } \\
\text { universo }\end{array}$ & 95,3 & 87,5 & 40,9 & 82,8 & 75,0 & 83,3 & 72,7 & 93,8 & 79,2 \\
\hline $\begin{array}{l}\text { Alimentos } \\
\text { transgênicos }\end{array}$ & 51,1 & 75,0 & 27,3 & 48,3 & 57,8 & 61,4 & 30,3 & 37,5 & 37,7 \\
\hline $\begin{array}{l}\text { Descarte de } \\
\text { embriões } \\
\text { excedentes }\end{array}$ & 27,9 & 61,9 & 23,8 & 37,9 & 51,2 & 36,4 & 69,7 & 62,5 & 62,3 \\
\hline
\end{tabular}

Fonte: Elaboração própria.

Em relação à aprovação de temas polêmicos, o curso de Física se destacou, obtendo os índices mais altos em quatro dos oito temas explorados (Tabela 2). A coordenadora do curso atribuiu esse índice à importância que os alunos de Física dão à ciência, uma vez que esses temas estão relacionados à busca de soluções para alguns dos problemas atuais da sociedade. Um dado que nos chamou a atenção foi o de os licenciandos em Química e Ciências Biológicas apresentarem percentuais maiores de aceitação sobre a origem do universo do que os do próprio curso de Física. Inferimos que esse fato possa estar relacionado às discussões sobre a natureza da ciência que são realizadas em disciplinas iniciais do curso de Física e que não constam na grade curricular dos demais cursos.

Outro dado interessante, que vai ao encontro da religiosidade explicitada pelos licenciandos, reflete o fato de os alunos do curso de Educação do Campo manifestarem índice menor de aceitação sobre a origem do universo $(40,9 \%)$ que os dos demais cursos. Entendemos que esse fato 
possa estar intimamente relacionado à frequência dos licenciandos (74\%) a suas "comunidades" religiosas (Gráfico 2).

Quando indagados sobre a teoria da evolução biológica (darwinismo), os licenciandos do curso de Ciências Biológicas, que estudam esse conteúdo mais profundamente, apresentam uma taxa muito baixa de rejeição a ela (2\%), enquanto nos outros cursos a porcentagem de rejeição ficou entre 20 e 30\%, com exceção de Educação do Campo, que apresentou índice de $75 \%$. Diante desse resultado, notamos que o conhecimento científico, para estes licenciandos, sofre influência religiosa, sendo que $54 \%$ dos alunos do curso de Educação do Campo não aceitam a teoria da evolução biológica, possivelmente por ir contra seus ensinamentos religiosos (Gráfico 4).

Aprofundando um pouco mais a temática evolução biológica (darwinismo), destaca-se que esse tema tem frequentemente sido objeto de profícuos embates em âmbito escolar. Em determinados cursos com perfis mais religiosos, há uma acentuada curva pela não aceitação ou rejeição de suas bases teóricas, como mostraram os dados referentes ao curso de Educação do Campo (Gráfico 4). E oportuno destacar que os alunos dos cursos em questão são professores em formação, ou seja, suas interpretações/posicionamentos podem culminar e influenciar sua futura atuação em sala de aula diante de discussões sobre ciência e religião. Nessa perspectiva, é oportuno mencionar o trabalho de Oliveira (2009) sobre a aceitação/rejeição da teoria da evolução biológica com alunos da educação básica. Segundo a autora, quando são feitas afirmações de evolução biológica ligadas a registros fósseis, por exemplo, há uma tendência de aceitação por parte dos alunos; por outro lado, quando a temática está associada à origem e à evolução da espécie humana, os alunos apresentam discordância. Esse cenário nos convida a refletir sobre o papel da mediação docente no enfrentamento desse contexto dúbio de interpretações e também na formação inicial de professores.

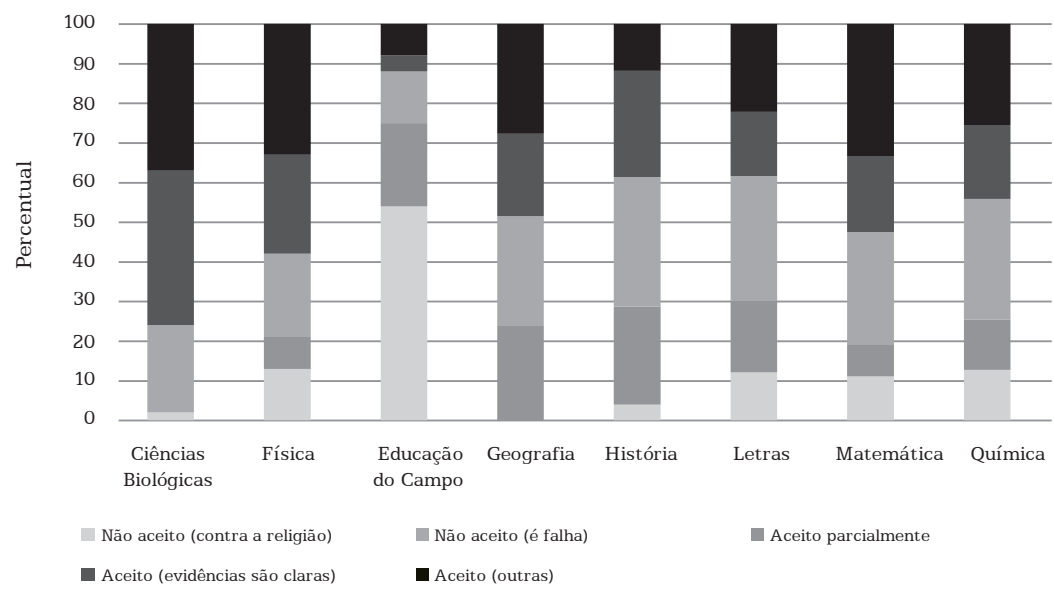

Gráfico 4 - Percepção dos alunos, em percentual, sobre a aceitação da evolução biológica, por curso

Fonte: Elaboração própria. 
Ainda sobre essa questão, comparamos as respostas dos alunos ingressantes e dos alunos concluintes (Gráfico 5). Os dados evidenciam que o índice de rejeição, entre o início e o fim do curso, diminui em todos os tipos de respostas e que o índice de aceitação aumenta claramente nas respostas que envolvem a análise pessoal do aluno, e não a opinião geral da comunidade científica. Mesmo que a teoria da evolução biológica não seja abordada na maioria dos cursos (exceto no de Ciências Biológicas), inferimos que o conhecimento adquirido pelos alunos durante os anos de graduação modifica suas crenças, ocasionando uma tendência de mais aceitação à teoria evolucionista.

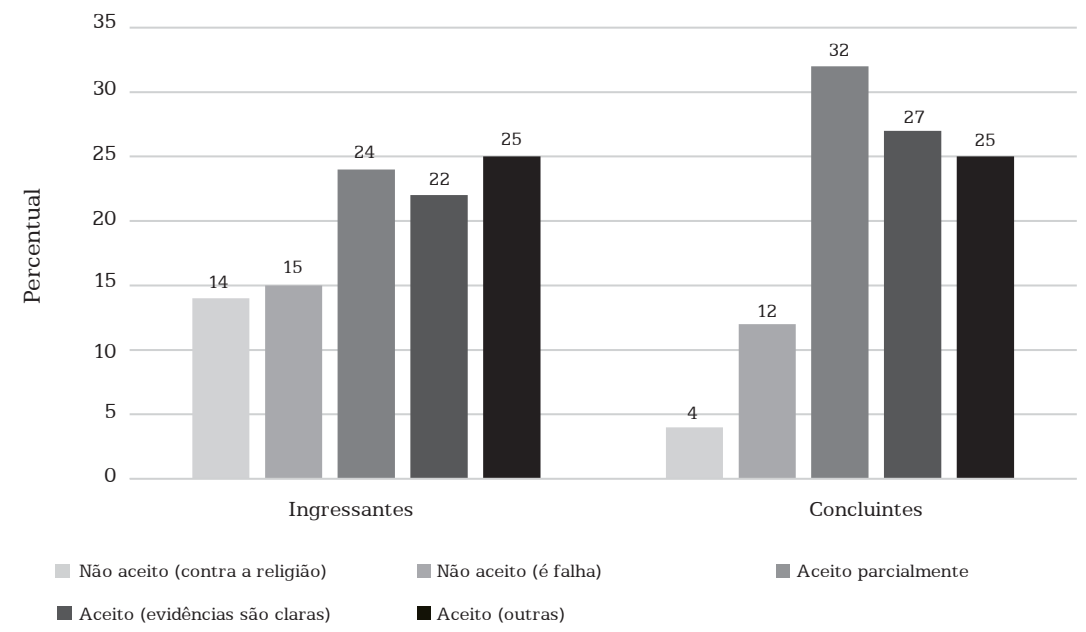

Gráfico 5 - Percepção dos alunos, em percentual, sobre a aceitação da evolução biológica, por momento acadêmico

Fonte: Elaboração própria.

Por fim, observamos que a análise quanto à relação aceitação/rejeição da evolução biológica, se considerada as religiões dos alunos, demonstra que entre ateus e agnósticos a média de aceitação ficou em 95\%; entre espiritualistas, 83\%; entre católicos, $73 \%$; e, entre evangélicos, apenas 34\%. Os cursos que obtiveram os índices de rejeição mais altos foram Educação do Campo, Física e Química.

Foi observado também que as discussões sobre a temática ciência e religião se acentuam quando abordados temas polêmicos com os alunos, por exemplo, a teoria evolucionista em diferentes vieses.

Em um viés científico, a concepção de evolução biológica pode ser simplificadamente entendida ante a mudança das características hereditárias de determinados grupos de organismos com o passar das gerações, atrelada a variabilidades genéticas de uma determinada população, bem como ante fatores de mutação gênica, cromossômica, e variabilidades estabelecidas por meio de seleção natural, por exemplo. Destacam-se os estudos, nessa direção, de pesquisadores como Jean-Baptiste de Lamarck, Charles Robert Darwin, Charles Lyell e Alfred Russel Wallace.

Em um viés religioso, a temática da evolução biológica suscita uma variedade de posicionamentos, de acordo com a religião dos alunos. Fazendo um tímido recorte, com foco no Cristianismo, podemos citar, por exemplo, o lançamento pela igreja católica, em 1950, de uma Encíclica Humani generis (Papa Pio XII), na qual tratou do que chamou de doutrina do evolucionismo, ou seja, a busca pela origem do corpo humano em matéria viva preexistente, 
mencionando que a fé (católica, no caso) obriga a aceitação de que as almas são criadas por Deus. Já no Espiritismo, o codificador Alan Kardec tratou da evolução espiritual e afirmou que a evolução material (do corpo do homem) deve ser dada pela ciência, já que ela fornece os dados que constituem a verdadeira gênese, segundo as leis da natureza.

Diante do exposto e refletindo sobre a formação inicial docente, a indagação sobre como preparar o futuro professor para levar a discussão ciência-religião para a sala de aula da educação básica torna-se um desafio para as instituições formadoras. Temática essa que tem ganhado visibilidade e amplitude no cenário nacional, no momento em que se discute a proposta da "Escola sem partido" (Projeto de Lei no 193/2016) no Congresso Nacional. Outras temáticas, como big bang, clonagem, células-tronco embrionárias, alimentos transgênicos, também poderiam fomentar e aprofundar o diálogo entre ciência e religião, contudo, devido à limitação de espaço neste artigo, seguimos a apresentação dos dados com foco em algumas análises realizadas.

Buscamos também investigar as concepções dos licenciandos a respeito da modificação do homem e de outros seres vivos no decorrer do tempo (Dorvillé, 2010).

Em um panorama geral, pode-se constatar que a maioria dos alunos $(84,9 \%)$ acredita que todos os seres vivos - inclusive o homem - se modificam ao longo do tempo. No entanto, em uma análise por curso, notamos que para 25\% dos licenciandos de Química e 20\% dos licenciandos de Letras o homem não se modifica ao longo do tempo (Gráfico 6).

Analisando as respostas enunciadas pelos licenciandos destes cursos, constatamos que tais alunos mencionaram ser religiosos (predominantemente católicos e evangélicos). Já os alunos que se identificaram como ateus ou agnósticos, ao contrário do grupo de alunos religiosos, concordaram com a afirmação de que os seres vivos, inclusive o homem, se modificam ao longo do tempo. Esse é um resultado interessante e que pode evidenciar a força da questão religiosa e sua influência nas respostas e no entendimento de mundo/ciência dos licenciandos.

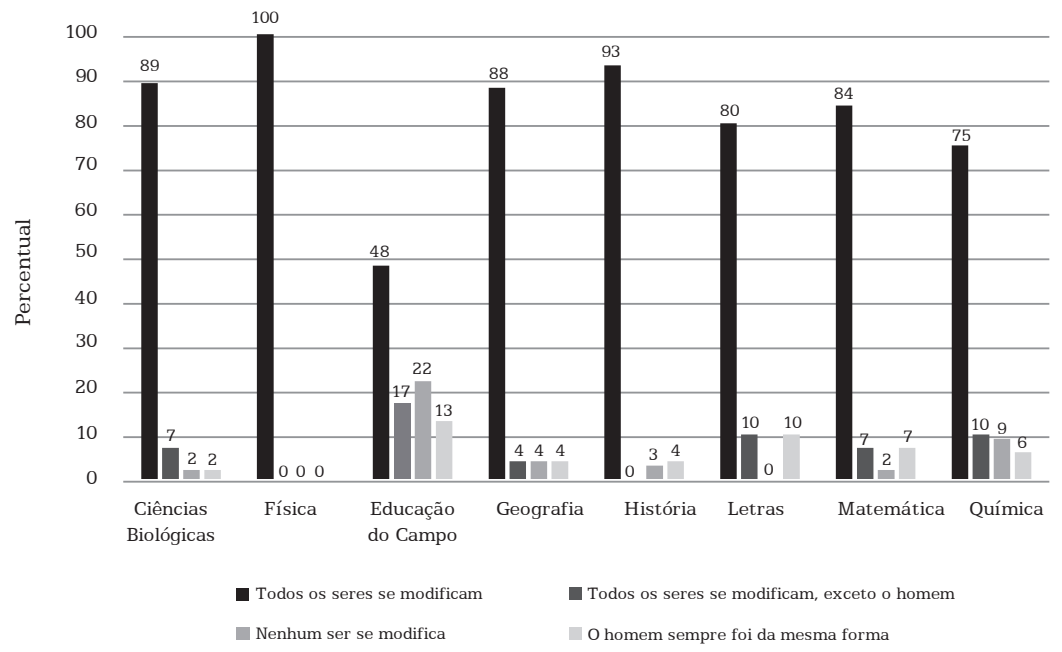

Gráfico 6 - Percepção dos alunos, em percentual, a respeito da modificação do homem e de outros seres vivos no decorrer do tempo, por curso

Fonte: Elaboração própria. 
Explorando um pouco mais a noção de transformação dos seres vivos, propusemos aos licenciandos que apontassem elementos que consideravam como mutáveis e como imutáveis com o passar do tempo. Nessa direção, explicitamos dez temas: homem, Deus, ciência, religião, leis da natureza, fé, conhecimento, verdade, passado e futuro. Para esta discussão, apresentamos apenas recorte dos temas abordados pelos alunos.

Em relação aos temas ciência e conhecimento, a crença na mutabilidade foi quase unânime entre os alunos ingressantes (97,3\%) e absoluta (100\%) entre os alunos concluintes. Quanto à concepção de mutabilidade de Deus, religião e fé, não encontramos um padrão nas respostas, ou seja, elas divergiram muito entre cursos e períodos (ingressantes e concluintes). Entendemos que esse achado possa estar vinculado a uma bagagem que os licenciandos já trazem consigo para a universidade.

No que tange à mutabilidade do passado, no curso de História o índice encontrado apresentou considerável diferença em relação à média dos índices dos demais cursos. Enquanto a maioria dos licenciandos dos outros cursos entende o passado como algo imutável, esse percentual é de 40,3\% no de História. Comparando ingressantes e formandos dentro deste curso, a concepção do passado como mutável é de $27,6 \%$ e 52,9\%, respectivamente. Questionado sobre esse resultado, o coordenador defendeu que, para os historiadores, o passado realmente tem caráter mutável. Segundo ele, se não fosse assim, não seria necessário, durante o curso, discutir e analisar a história em vieses diferentes; destacou, nessa direção, ser um fato importante os licenciandos de História possuírem tal concepção.

Sobre a origem do universo, buscamos investigar qual a visão dos licenciandos, em nível de aceitação ou rejeição, sobre duas perspectivas: a primeira, a da criação do universo a partir do big bang; a segunda, a de que o universo sempre existiu (Souza et al., 2009, questão adaptada). Comparando as visões de ingressantes e concluintes, encontramos que próximo de $100 \%$ dos concluintes aceitam parcialmente a teoria do big bang. Esse resultado possivelmente se justifica diante da importância que essa teoria tem para os estudos e descobertas cosmológicas. Em conversa com os coordenadores, apuramos que, apesar desse resultado, o único curso que discute teorias sobre a origem do universo é o de Física, em especial na disciplina de Astronomia. Destaque para o dado de que 63,6\% dos alunos ingressantes do curso de Educação do Campo rejeitam a teoria do big bang.

Também buscamos questionar os licenciandos sobre a possibilidade de a ciência aceitar e/ou explicar a religião e vice-versa. Os resultados evidenciaram que, para a maioria deles (cinco dos oito cursos), a afirmativa de que "um dia a religião aceitará a ciência" é plausível (Gráfico 7). Já a assertiva de que "um dia a ciência aceitará a religião" se sobressaiu apenas no curso de Educação do Campo.

É importante destacar que a visão de que a ciência não precisa ser aceita pela religião pode ser percebida em diferentes momentos da história humana, mais evidentemente durante o iluminismo e o surgimento do positivismo, em que a razão predominou sobre a teologia e a metafísica. Nessa vertente, existem fortes concepções de que a ciência desvinculada da religião produz resultados mais condizentes com os fenômenos da natureza, corroborando com a visão dos licenciandos de que a ciência tem um caráter de mutabilidade. 


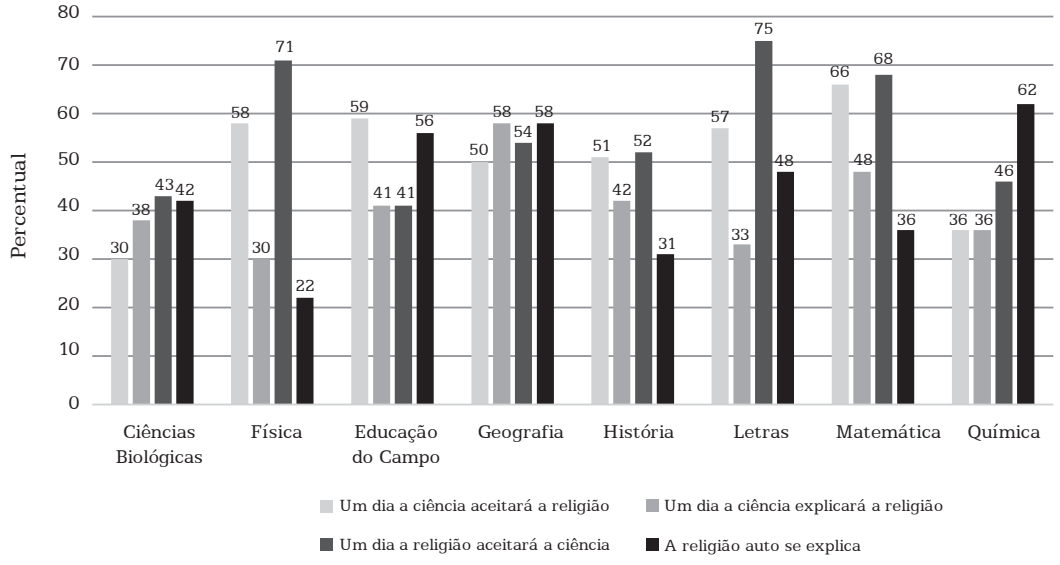

Gráfico 7 - Percepção dos alunos, em percentual, sobre a possibilidade de a ciência aceitar e/ou explicar a religião e viceversa, por curso

Fonte: Elaboração própria.

Aprofundando a investigação, buscamos inquirir a leitura que os licenciandos tinham da dicotomia ciência e religião em um contexto de sala de aula. Inicialmente, eles foram indagados sobre se as concepções religiosas dos alunos atrapalham ou não o ensino de ciências nas escolas. Para 69\% dos licenciandos, a resposta foi sim, ou seja, a maior parte deles entende que as concepções religiosas têm influência sobre a aprendizagem de ciência. O curso de Ciências Biológicas foi o que apresentou o maior número de alunos com essa percepção, seguido do curso de Física (Gráfico 8). Inferimos das análises realizadas e das entrevistas com os coordenadores que alunos de cursos que trabalham em suas grades curriculares conceitos e conteúdos que podem ser confrontados com ideais religiosos - por exemplo, Ciências Biológicas, em que se abordam questões evolucionistas, e Física, em que se discute a origem do universo - são mais propensos a defenderem que as concepções religiosas influenciam no ensino de ciências.

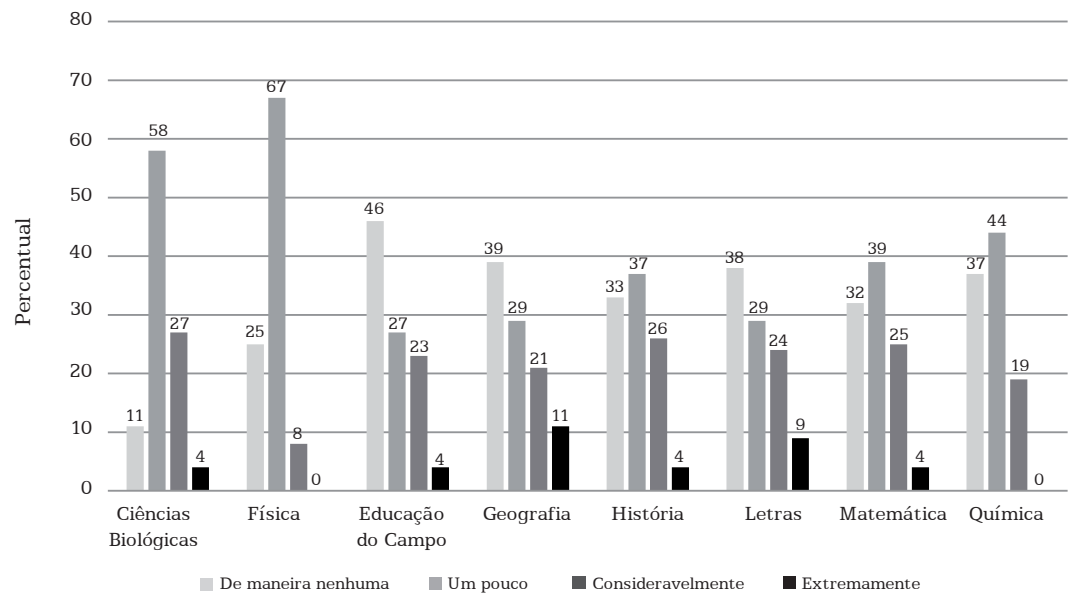

Gráfico 8 - Percepção dos alunos, em percentual, sobre a influência da religião no ensino de ciências, por curso

Fonte: Elaboração própria. 
De modo a melhor entender esse resultado, realizamos uma nova leitura dos dados, agora separando licenciandos que declararam ter religião daqueles que declararam não ter religião (Gráfico 9). Como esperado, para os primeiros, há uma leve tendência a acreditar que as concepções religiosas não influenciam ou influenciam pouco no ensino de ciências. Apenas para $18 \%$ dos alunos essa influência ocorre. Por outro lado, para os alunos que declararam não ter religião, esse valor mais que dobra, ou seja, para $41 \%$ dos licenciandos, a religiosidade influencia, sim, no ensino de ciências nas escolas.
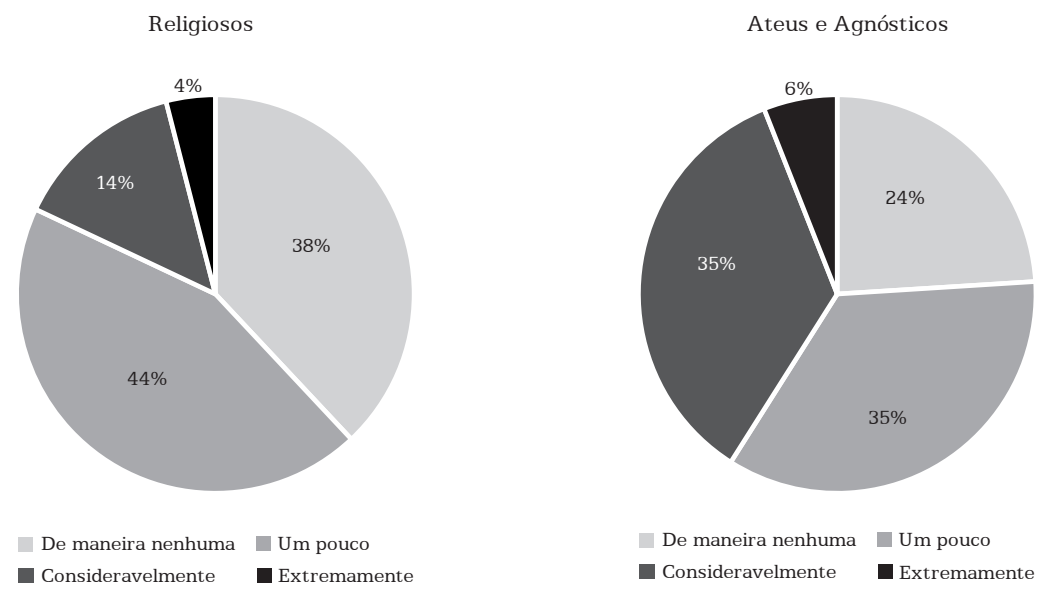

\section{Gráfico 9 - Percepção dos alunos, em percentual, sobre a influência da religião no ensino de ciências, por religião}

Fonte: Elaboração própria.

Cabe destacar, ainda, a percepção dos licenciandos sobre como o professor deve proceder em situação de questionamento religioso durante as aulas (Henrique; Silva, 2011). São variadas as respostas dadas por alunos ingressantes e concluintes (Gráfico 10). Há uma significativa porcentagem de licenciandos concluintes que preferem comentar, discutir e/ou opinar sobre o tema ciência e religião, quando o assunto é questionado em sala de aula. Esse resultado demonstra que os alunos concluintes são mais abertos ao diálogo do que os ingressantes, optando, hipoteticamente, por um enfrentamento em detrimento da fuga de uma discussão sobre a temática em sala de aula. 


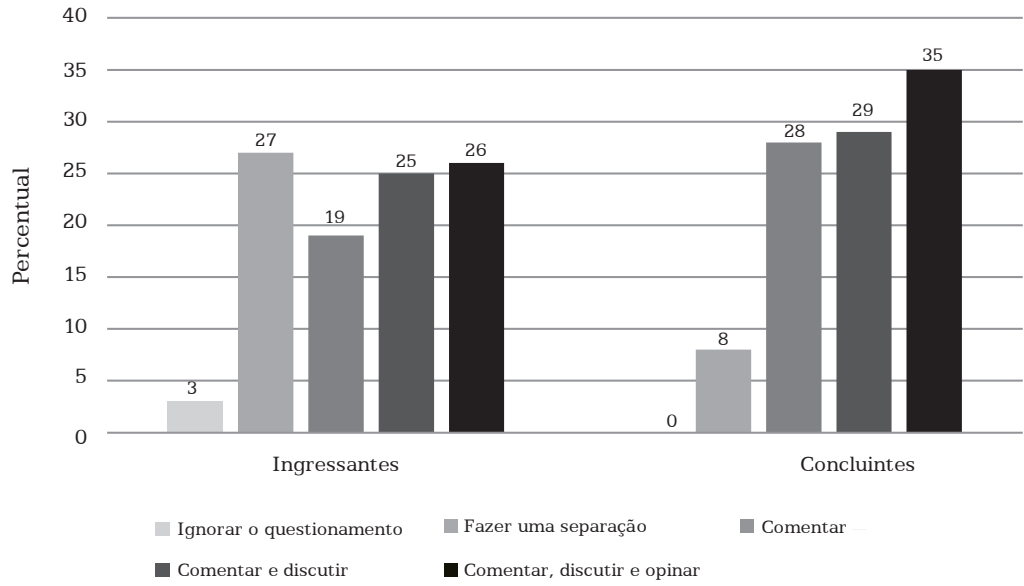

Gráfico 10 - Percepção dos alunos, em percentual, sobre o comportamento esperado do professor acerca de eventuais questionamentos religiosos em sala de aula, por momento pedagógico

Fonte: Elaboração própria.

Ao entrevistarmos os coordenadores dos cursos, obtivemos um conjunto de respostas parecidas, em que eles apresentaram como característico dos cursos o objetivo de promover o diálogo e de demonstrar diferentes pontos de vista sobre o mesmo aspecto, a fim de que o próprio aluno crie sua visão de mundo, mas, ainda sim, aceite opiniões divergentes. Os dados da pesquisa evidenciaram que esse objetivo tem sido alcançado, visto que a opção de resposta "ignorar o questionamento" não foi selecionada por nenhum aluno concluinte.

Nosso resultado vai ao encontro dos resultados da pesquisa de Henrique e Silva (2011), realizada com licenciandos em Ciências Exatas da USP, que mostrou que, para $20 \%$ dos alunos, é necessário o diálogo; de acordo com esses alunos, o professor pode manifestar sua opinião, mas deve buscar não influenciá-los. Embora essa tendência ao diálogo também esteja demonstrada nas análises que realizamos no contexto da UFTM, ela ocorreu de forma ínfima nos cursos de Matemática e Ciências Biológicas.

Ao apresentarmos os resultados ao coordenador do curso de Matemática, ele foi enfático em afirmar que discussão de temas polêmicos e/ou controversos não faz parte da proposta curricular do curso, o que pode ser um indício à tendência de não mudança na visão dos alunos. Em relação ao curso de Ciências Biológicas, o coordenador, que é o professor da disciplina de Evolução, recebeu com surpresa esse resultado. Para ele, uma justificativa para esses dados pode estar ligada ao fato de que muitos alunos concluintes fizeram essa disciplina com outro professor que não se encontra mais na UFTM e que pode ter influenciado o resultado.

As discussões por ora realizadas representam um recorte dos dados levantados pela presente pesquisa e permitiram entender um pouco da visão 
de licenciandos da UFTM, futuros professores na educação básica, sobre a relação ciência e religião. Ademais, também indicaram aproximações e afastamentos entre as percepções de ingressantes e concluintes ante as temáticas abordadas. Nas entrevistas com os coordenadores, pudemos observar que parte dos dados apresentados não correspondia ao que era esperado por eles, promovendo falas como: "[...] com esses dados que você me trouxe [...] se pegarmos a realidade do país e jogarmos em cima do nosso curso, nós vemos que nosso curso está na contramão". Por outro lado, alguns dados apresentados corroboraram as preconcepções de alguns coordenadores sobre seus cursos, em especial os relatos da coordenadora do curso de Educação do Campo.

\section{Considerações finais}

Ao final desta investigação, constatamos que as concepções sobre ciência e religião dos alunos de licenciatura da UFTM variaram bastante por curso e, dentro de um mesmo curso, tais concepções variaram entre ingressantes e concluintes. Diversos apontamentos sobre a temática foram realizados pelos licenciandos, trazendo subsídios para a autorreflexão, para a reflexão de seus formadores (na universidade) e para o futuro trabalho em sala de aula (na educação básica).

Entre esses apontamentos, destaca-se a importância dada pelos alunos ao trabalho, em sala de aula, da relação ciência-religião de maneira neutra e reflexiva. Fato esse que se maximiza em relevância quando entendemos que a escola é um ambiente em que a opinião dos alunos sobre determinados temas ainda não está totalmente estabelecida e que a influência do professor pode ser crucial. Corroborando essa constatação, Azevedo e Carvalho (2017, p. 264) em um levantamento e análise de 100 pesquisas nacionais, publicadas em forma de teses e dissertações entre os anos de 1991 e 2016, que abordaram a temática ensino de ciências e religião identificaram que a maioria dos trabalhos "defende que a abordagem da temática, embora delicada, é um caminho para uma melhor compreensão da construção do conhecimento científico, de suas potencialidades e limitações [...]". Acrescentam ainda que tais discussões são importantes para a "construção de uma sociedade mais crítica e aberta ao diálogo".

Entendemos que esta pesquisa pode contribuir, mesmo que de forma diagnóstica, para que os coordenadores e os professores da UFTM tenham um panorama geral das visões de mundo trazidas (e construídas ao longo do curso) pelos licenciandos sobre ciência, religião e suas inter-relações. Dessa forma, pode propiciar momentos de diálogo/reflexão no sentido de formar futuros professores com a vivência em discussões sobre o tema.

Apesar de toda a relevância sociocultural e histórica, vemos que a temática "ciência e religião" ainda encontra muita resistência e pseudodebates no meio acadêmico. Dessa forma, entendemos que essa discussão, em âmbito dos cursos de licenciatura da UFTM, não se esgota com esta pesquisa. Esperamos dar continuidade a este trabalho explorando ainda mais essa temática de modo que possamos contribuir não apenas com o (re)pensar a formação inicial de professores, mas também com a futura atuação desse profissional na educação básica 


\section{Referências}

ALEXANDER, D. R. Models for relating science and religion. Faraday Paper, Cambridge, n. 3, p. 1-4, 2007. Disponível em: <https://faradayinstitute.org/resources/Faraday\%20Papers/Faraday\%20Paper\%203\%20 Alexander_EN.pdf>. Acesso em: 10 out. 2018.

AZEVEDO, H. L.; CARVALHO, L. M. O. Ensino de ciências e religião: levantamento das teses e dissertações nacionais produzidas entre $1991 \mathrm{e}$ 2016 que abordam essa relação. VIDYA, Santa Maria, v. 37, n. 1, p. 253272, jan./jun. 2017.

BOGDAN, R.; BIKLEN, S. K. Investigação qualitativa em educação: uma introdução à teoria e aos métodos. Porto: Porto Editora, 1994.

BRASIL. Senado Federal. Projeto de Lei do Senado no 193, de 2016. Inclui entre as diretrizes e bases da educação nacional, de que trata a Lei no 9.394, de 20 de dezembro de 1996, o "Programa Escola sem Partido". Brasília, DF, 2016. Disponível em: < https://legis.senado.leg.br/sdleggetter/documento $\mathrm{dm}=3410752 \& \mathrm{ts}=1545350833160 \&$ disposition $=\mathrm{inl}$ ine >. Acesso em: $27 \mathrm{dez} .2018$.

DORVILLÉ, L. F. M. Religião, escola e ciência: conflitos e tensões nas visões de mundo de alunos de uma licenciatura em ciências biológicas. 2010. 357 f. Tese (Doutorado em Educação) - Faculdade de Educação, Universidade Federal Fluminense, Niterói, 2010.

EL-HANI, C. N.; SEPÚLVEDA, C. Quando visões de mundo se encontram: religião e ciência na trajetória de formação de alunos protestantes de uma licenciatura em ciências biológicas. Investigações em Ensino de Ciências, Porto Alegre, v. 9, n. 2, p. 137-175, ago. 2004.

FORATO, T. C. M.; PIETROCOLA, M.; MARTINS, R. A. História da ciência e religião: uma proposta para discutir a natureza da ciência. In: SIMPÓSIO NACIONAL DE ENSINO DE FÍSICA, 17., 2007, São Luís. Resumos... São Luís: SBF, 2007. Disponível em: <http://www.sbf1. sbfisica.org.br/eventos/snef/xvii/sys/resumos/T0190-1.pdf >. Acesso em: 09 fev. 2018.

GIL, A. C. Métodos e técnicas de pesquisa social. 6. ed. São Paulo: Atlas, 2008.

HENRIQUE, A. B.; SILVA, C. C. Comparando os objetivos e métodos da ciência e religião na formação de professores. In: ENCONTRO NACIONAL DE PESQUISA EM ENSINO DE CIENCIAS, 8., 2011, Campinas. Resumos... Campinas: Abrapec, 2011. Disponível em: <http:// abrapecnet.org.br/atas_enpec/viiienpec/resumos/R0133-1.pdf $>$. Acesso em: 05 jan. 2018. 
LIMA, A. P.; MENIN, M. S. S. O papel dos valores religiosos em escolas públicas do interior paulista. Revista Ibero-Americana de Estudos em Educação, Araraquara, v. 1, n. 2, p. 143-151, jul./dez. 2006.

LOVING, C.; FOSTER, A. The religion in the science classroom issue: seeking graduate student conceptual change. Science Education, Hoboken, v. 84, n. 4, p. 445-468, June 2000.

LÜDKE, M.; ANDRÉ, M. E. D. A. Pesquisa em educação: abordagens qualitativas. São Paulo: EPU, 1986.

MACIEL, D. A. G. C.; BARBOSA, M. L. F. F. "Ah, eu acho a oralidade importantíssima!": a propósito da prática docente no ensino da oralidade. Educação: Teoria e Prática, Rio Claro, v. 23, n. 44, p. 63-80, set./dez. 2013.

MANDÚ, T. M. C.; AGUIAR, M. C. C. A formação inicial no curso de pedagogia: concepções, caminhos e perspectivas dos estudantes. Educação Temática Digital, Campinas, v. 15, n. 3, p. 560-577, set./dez. 2013.

OLIVEIRA, G. S. Aceitação/rejeição da evolução biológica: atitudes de alunos da educação básica. 2009. 162 f. Dissertação (Mestrado em Educação) - Faculdade de Educação, Universidade de São Paulo, São Paulo, 2009.

SOUZA, R. F. et al. Evolucionismo versus Criacionismo: aceitação e rejeição no século 21. Ciência Hoje, São Paulo, v. 43, n. 256, p. 36-41, jan./fev. 2009. Disponível em: <http://www.uel.br/pessoal/rogerio/ evolucao/textos/evolucionismo256.pdf >. Acesso em: 10 out. 2018.

WOOLNOUGH, B. On the fruitful compatibility of religious education and science. Science \& Education, Berlin, v. 5, n. 2, p. 175-183, Apr. 1996.

Recebido em 6 de março de 2018.

Aprovado em 29 de outubro de 2018. 